\title{
Quantifying Vulnerability to Poverty in a Developing Economy
}

\author{
RASHIDA HAQ
}

\section{INTRODUCTION}

The concept of vulnerability extends the idea of poverty to include idiosyncratic as well as aggregate risks which can be defined as the probability of being in poverty or to fall deeper into poverty in the future. It can be categorised on the micro-and macro level where macro vulnerability refers to worldwide threats to social welfare, e.g. globalisation and recent international financial crises. Conversely, micro vulnerability refers to the household level risks including health risks, economic shocks, social shocks, natural disasters, and demographic shocks [Tesliuc and Lindert (2004)]. To assess and estimate vulnerability to poverty, various approaches had been proposed. First, vulnerability can be seen as a probability of falling into poverty in near future [Chaudhuri (2003); Christaensen and Subbarao (2005)]. The other ways of measuring vulnerability consider it as low expected utility [Ligon and Schechter (2003)] and vulnerability as uninsured expose to risk, i.e., measures of cost, in terms of consumption [Tesliuc and Lindert (2004)]. The basic idea is that the state of poverty at a given point actually is not sufficient for assessing poverty and for drawing results to design poverty reduction programs. Households face various risks and do not know whether any possible shock will hit them in future. So the assessment of poverty at a given point in time is a static approach, not considering possible changes in the future. By assessing vulnerability it refers to the dynamic perspective, it is explicitly forward looking and tries to include the risks that may push people into poverty in future.

Although there are different concepts of poverty and vulnerability which are closely related due to two established facts; (i) the poor are typically most exposed to diverse risks, and (ii) the poor have the fewest assets to deal with these risks. However, the importance of vulnerability because if policymakers design poverty alleviation policies in the current year on the basis of a poverty threshold of income or consumption in the previous year, 'the poor' who receive income support may have already escaped from poverty and 'the non-poor' who do not receive such support may have slipped into poverty due to various unanticipated shocks. Hence, assessing vulnerability helps to distinguish between ex-ante poverty prevention interventions and ex-post poverty alleviation strategies like mitigation and coping arrangements [Holzmann and Jorgensen (2000)].

Rashida Haq <rashida@pide.org.pk> is Senior Research Economist, Pakistan Institute of Development Economics, Islamabad. 
Households and communities in Pakistan face the risks of suffering from different types of shocks. Some shocks affect communities as a whole referred as covariate shocks such as economic and financial crises and natural disasters. Others affect one or a few households noted as idiosyncratic shocks, such as a death of a household member or loss of a job. The analysis of vulnerability proposed is crucial for determining which programs to have in place and when to introduce them or adjust their levels and coverage. To make these decisions, policymakers need to have access not only to macro-economic indicators, but also to indicators that provide an understanding of household-level of vulnerability and risk profiles and risk management mechanisms, particularly for the poor. The vulnerability analysis can be useful in the context of Pakistan, given the large proportion of poor people and the low level of human capital as Pakistan is categorised in low human development countries ranked at 146 out of 187 countries with human development index value of 0.537 [UNDP (2014)].

The main purpose of this paper is therefore to: (a) generate the poverty vulnerability indices of the households using expected and variance of consumption expenditures in Pakistan; (b) estimate incidence, intensity and severity of poverty; (c) contribution of vulnerability to poverty (d) estimates of vulnerability and poverty across different socio economic groups; and (e) determinants of vulnerability. The analysis carried out in the paper uses Pakistan Panel Household Survey (PPHS)-2010. Expected results from the analyses are judged to be more relevant to poverty policy formulation in Pakistan.

The rest of the paper is structured as follows. Section 2 provides review of literature. Section 3 outlines the details of the methodology and data. The econometric and other relevant results are presented in Section 4. Section 5 concludes the study highlighting some of the policy issues for reducing poverty and vulnerability to poverty in Pakistan.

\section{REVIEW OF LITERATURES}

The existing literature, which intends to estimate the aggregate vulnerability of households, has been pioneered by Townsend (1994) and Udry (1995), who were some of the first using panel data to analyse, whether households are able to insure their consumption against idiosyncratic income fluctuations over space and time. In this spirit several studies followed analysing consumption fluctuations over time [e.g. Dercon and Krishnan (2000); Jalan and Ravallion (1999); Morduch (2005)], concluding that households are partly but not fully capable of insuring consumption against income fluctuations. A severe drawback of this literature is that it relies on panel data, which is very limited for developing countries.

The second strand of empirical literature on vulnerability, which estimates the impact of selected shocks on households' consumption, has its limitations because information on idiosyncratic and covariate shocks is in most households' surveys very limited or sometimes missing [Günther and Harttgen (2005)]. As a consequence most authors have only been able to focus on the impact of selected shocks on consumption [Dercon and Krishnan (2000); Gertler and Gruber (2002)]. Moreover, these studies have rarely been able to analyse the impact of these shocks on the vulnerability of households. Several measurements to analyse vulnerability to poverty have recently been proposed, 
empirical studies are still rare as the data requirements for these measurements are not met by the surveys that are available for most developing countries.

In recent debates on poverty in Pakistan, the issue of vulnerability have been mentioned frequently [Pakistan (2010); World Bank (2002)]. Furthermore, the poverty incidence in KP province is higher and agriculture is more risky than in other parts of Pakistan. Kurosaki (2010) showed that most of the vulnerability measures summarise micro-level information on consumption and income, since the welfare of an individual depends not only on consumption but also on other non-monetary aspects such as education and health in case of KP province.

The literature on risk and vulnerability by using a cross-section survey to map and quantify shocks from all sources, ex-post responses and outcomes for a sample of relatively poor Pakistani households was explored by Heltberg and Niels (2009). They found high incidence and the cost of shocks, with health-related shocks easily the worst. These findings add to the evidence that health shocks often dominate and impose severe coping costs in terms of medical expenses while relying mostly on informal and ad hoc responses: informal borrowing, spending savings, and working more were the most frequently used responses. The extent of household vulnerability to poverty in Pakistan was also estimated by Jamal (2009) who found that about 52 percent population was vulnerable to poverty during 2004-05 while rural headcount ratio in terms of household vulnerability is relatively high as compared to the vulnerability incidence in urban areas. Although monetary poverty has declined during the period 2001-05, the relative incidence of vulnerability has increased from 50 percent in 2001 to 52 percent in 2005.

This review of literatures on shocks, poverty and vulnerability indicating direct implications for welfare loss due to health shock, agricultural shock and natural disaster etc., ultimately, translated in income shock.

\section{DATA AND METHODOLOGY}

\section{(a) Data Collection}

Ideally, vulnerability measurement would require a long panel data. However, for many developing countries, reliable panel data are scarce and only cross-sectional survey data are available. Pakistan is no exception in this regard. The absence of panel data obliges us, in our assessment of vulnerability to poverty in Pakistan, to adopt the approach proposed by Chaudhuri (2003) which is particularly designed for cross-section data.

This study is based on a cross-section data from 'Pakistan Panel Household Survey (PPHS)-2010' conducted by Pakistan Institute of Development Economics financed by the World Bank. The households' sample of PPHS was selected on the basis of a multistage stratified sampling procedure. The survey consists of 16 districts from four provinces (Punjab, Sindh, Khyber Pakhtunkhwa (KP) and Balochistan) with their urban and rural counterparts. The districts included are Attock, Faisalabad, Hafizabad, Vehari, Muzaffargarh, and Bahawalpur in Punjab; Badin, Mirpur Khas, Nawab Shah, and Larkana in Sindh; Dir, Mardan, and Lakki Marwat in Khyber Pakhtunkhwa (KP); and Loralai, Khuzdar, and Gwadar in Balochistan. 
The total sample size of PPHS-2010 was 4142 households; 2800 in rural and 1342 in urban (Punjab1878; Sindh 1211; KP 601 and Baluchistan 452). After cleaning the data (deleting outliers, no responses and missing cases) a sample of 3500 households was selected for final analysis. The analysis was based on this information together with other information concerning characteristics of the head of the household (i.e., individual characteristics such as sex, age, education) and household characteristics, like household size (taken as adult equivalent), dependency ratio, ${ }^{1}$ poverty status, ${ }^{2}$ quality of house-whether mud house or brick house, agricultural land ownership, livestock ownership (large or small animals), log per adult equivalent consumption expenditure, in addition to community characteristics likes, regions and provinces. The shocks variables included are divided into a number of broad categories: natural/agricultural; economic; political/ social/legal; and demographic/life-cycle shocks that inflict welfare loss. Natural/ agricultural shocks include flooding, drought, fire, earthquake but also erosion and pestilence affecting crops or livestock. Economic shocks include business closures, mass layoffs, job loss, wage cuts, loss of remittances and other reasons. Social shocks in Pakistan include court cases and bribery, as well as long duration general strikes, violence, crime and political unrest. Health/life-cycle shocks include death, injury and illness of household members. The survey distinguished between death of the primary income earner and death of other household members. Similarly, the respondents were also asked whether the household was affected by idiosyncratic or covariate shocks and with the value of cost of burden.

So finally, in addition to these questions about specific shocks, households were also asked about the most important coping strategies to manage the reduction in income such as (i) asset-based strategies (sale of assets including land, livestock and stored crop); (ii) assistance-based strategies (help from friends and relatives); (iii) borrowing-based strategies (from friends and relatives, banks, NGOs and money lenders); and (iv) behaviour-based strategies (decrease food/non-food consumption, increase labour supply particularly of women and children, dropped out of school and beggary) .

\section{(b) Methodology}

In this section the detailed estimation procedure of the analysis of vulnerability to poverty in Pakistan is delineated as follow:

\section{Model Specifications}

\section{(i) Foster, Greer, Thorbecke (1984) Poverty Measure}

The methodology that is used in this analysis is the class of poverty measures by Foster, Greer and Thorbecke (FGT) which is widely used because they are consistent and additively decomposable [Foster, et al. (1984)].

$$
\begin{array}{lllllll}
P_{\propto}=\frac{1}{n} \sum_{i=1}^{q}\left(\frac{Z-C_{i}}{Z}\right)^{\propto} & \ldots & \ldots & \ldots & \ldots & \ldots & \ldots
\end{array}
$$

${ }^{1}$ The dependency ratio takes the sum of the population under the years of 15 and over 64 and divided by the population in the intermediate range of 15-64. 
Where $Z$ is the poverty line measured as per adult equivalent consumption expenditure of Rs $1671.89, C i$ is the $i t h$ welfare indicator measured in terms of per adult equivalent consumption expenditure, $n$ is the total households, $q$ is the number of households who are below the poverty line, and $\alpha \geq 0$ is a 'poverty aversion' parameter. The FGT poverty measure formula delivers a set of poverty indices, i.e. incidence $(\alpha=0)$, intensity or poverty gap $(\alpha=1)$ and severity of poverty $(\alpha=2)$.

\section{(ii) Vulnerability - the Probability of Being Poor in the Future}

Modeling the Probability of Becoming Poor: In order to analyse the effect of some idiosyncratic and covariate shocks on households' consumption expenditures, the approach proposed by Chaudhuri (2003) and Chaudhuri, et al. (2002) and Suryahadi and Sumarto (2003) developed particularly for cross-section data is used. Vulnerability in this context is defined as expected poverty, or in other words as the probability that a household's consumption will lie below the predetermined poverty line in the near future. Following Chaudhuri (2000), for a given household h, the vulnerability is defined as the probability of its consumption being below poverty line at time $t+1$ :

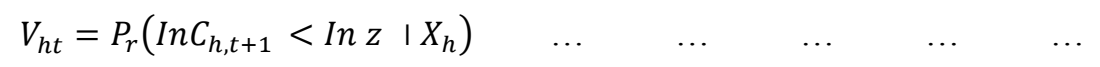

where $V_{h t}$ is vulnerability of household $h$ at time t, $C_{h, t+1}$ denote the consumption of household $h$ at time $\mathrm{t}+1$ and $Z$ stands for the poverty line.

For generating per adult consumption expenditure $\left(C_{h}\right)$ of $h$ household is given as:

$$
\begin{array}{llllllll}
L n C_{h}=X_{h} \beta+e_{h} & \ldots & \ldots & \ldots & \ldots & \ldots & \ldots
\end{array}
$$

where $X_{h}$ represents individual and household characteristics, $\beta$ is a vector of parameters, $e_{h}$ is the error term.

Suppose the variance of $e_{h}$ is given by:

$$
\begin{array}{lllllllll}
\sigma_{e, h}^{2} X_{h} \theta & \ldots & \ldots & \ldots & \ldots & \ldots & \ldots & \ldots
\end{array}
$$

To measure the parameters of $\beta$ and $\theta$, a three-stage feasible generalised least square (FGLS) procedure is used. In the first stage, equation 3 is to be estimated with ordinary least square (OLS) method and the square of the generated error terms are to be regressed against the independent variables to generate the predicted values of the error terms.

$$
\hat{\mathrm{e}}_{\text {OLS,h }}^{2}=X_{h} \theta+\eta_{h} \quad \ldots \quad \ldots \quad \ldots \quad \ldots \quad \ldots \quad \ldots \quad \ldots
$$

The predicted values of the error terms in Equation 5 are used to transform the same equation in a manner specified below:

$$
\frac{\hat{\mathrm{e}}_{O L S, h}^{2}}{X_{h} \hat{\theta}_{O L S}^{\wedge}}=\left[\frac{X_{h}}{X_{h} \theta_{O L S}^{\wedge}}\right] \theta+\left[\frac{\eta_{h}}{X_{h} \theta_{O L S}^{\wedge}}\right] \quad \ldots \quad \ldots \quad \ldots \quad \ldots \quad \ldots
$$

Equation 6 will be estimated using OLS method to obtain an asymptotically efficient FGLS estimate denoted as $\theta_{F G L S}^{\wedge}$. In this case, $X_{h} \theta_{F G L S}^{\wedge}$ is a consistent estimate of, $\sigma_{e, h}^{2}$ variance of the idiosyncratic component of households' consumption expenditures. Therefore, equation 3 is to be transformed with FGLS 


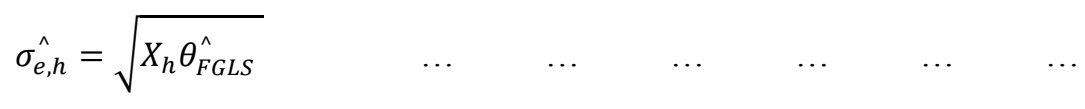

To obtain

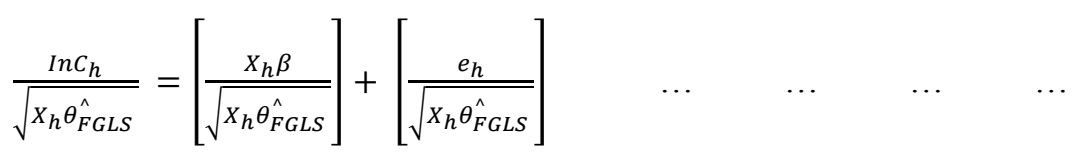

Equation 8 is to be estimated using FGLS method, and it yields a consistent and asymptotically efficient estimate of $\beta$. The expected log consumption can be estimated by using the estimates of $\beta^{\wedge}$ and $\theta^{\wedge}$. In this case, it can be noted as:

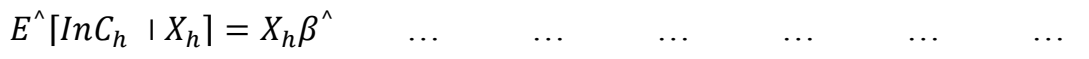

The variance of log consumption expenditure for each of the $h^{\text {th }}$ household is given as:

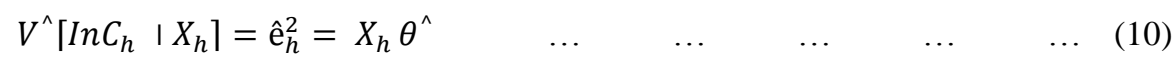

The vulnerability level of $h$ household, which is the probability that household $h$ with characteristics $X_{h}$ will be poor in the future can be estimated by assuming that households' consumption expenditures are log normally distributed. Therefore, suppose (.) $\Phi$ denotes the cumulative density of the standard normal distribution, probability of vulnerability can be computed as:

$$
V_{h}^{\wedge}=P_{r}^{\wedge}\left(\operatorname{In} C_{h}<\operatorname{In} z \quad \mid X_{h}\right)=\Phi\left[\frac{\operatorname{In} z-X_{h} \beta^{\wedge}}{\sqrt{X_{h} \theta^{\wedge}}}\right] \quad \ldots \quad \ldots \ldots
$$

According to Chaudhuri, et al. (2002), a vulnerability threshold of 0.5 is applied, indicating that a household with a 50 probability of falling into poverty is vulnerable to poverty at least once in the next years.

\section{(iii) Measuring Determinants of Vulnerability}

Risk signifies the possibility of adverse effects in the future. It derives from the interaction of social and environmental processes, from the combination of physical hazards and the vulnerabilities of exposed elements. The negative evens are not the sole driver of risk, and there is high confidence that the levels of adverse effects are in good part determined by the vulnerability and exposure of societies and social-ecological systems [UNISDR (2004)]. A logistic regression model as specified by Gujarati (2012) is used to examine the determinants of vulnerability to poverty in Pakistan. The vector of independent variables measuring individual characteristics for household head (gender, age, education), households characteristics (household size, dependency ratio, poverty status, housing quality, productive assets), transitory components (agricultural, social, economic and health shocks, four types of coping strategies) and place of residence (urban/rural and four provinces). 


\section{ANALYSIS}

In order to determine the effect of some idiosyncratic and covariate variables on households' consumption expenditures, the approach of Chaudhari (2000) to generate vulnerability indices with single point consumption data is used. At the same time to get three poverty estimates, a class of decomposable poverty measures by Foster, Greer and Thorbecke (FGT) has been adopted. It is worth noticing that the target of policy in this paper is a population of households, not individuals, simply because the data on consumption expenditures are obtained from the household surveys. This means that if we consider a household as poor or vulnerable every member in this household is deemed equally poor or vulnerable. The poverty and vulnerability estimates based on micro data from PPHS-2010 are presented in Table 1. It was analysed that 20.6 percent households in Pakistan are poor while 34.4 percent households are vulnerable to poor in future which is much higher than the point-in-time estimates of poverty, thus, signifies the importance of forward looking poverty analysis. The distribution of population by poverty status can be decomposed in vulnerable and non-vulnerable households indicating that 95.2 percent household will be remain poor in future while only 4.8 percent will be nonvulnerable in next year. It is important to note that 57.1 households are both poor and vulnerable while 42.9 percent are non-poor and vulnerable. Jamal (2009) estimated poverty level at 29.8 percent in 2005 and 33.7 percent in 2001 while vulnerability is 51.62 percent and 49.88 percent, respectively for these two periods. A measure of vulnerability was also developed using a fiveyear panel for rural Pakistan, which had illustrated that on average 67 percent households are vulnerable between 1986 to 1990 [Mansuri and Andrew (2002)]. It can be concluded that both poverty and vulnerability had decreased in Pakistan while a sizable fraction of non-poor households are vulnerable to poverty.

Table 1

Vulnerability and Poverty at Household Level: 2010

\begin{tabular}{|c|c|c|c|}
\hline \multirow[b]{2}{*}{ Vulnerability } & \multicolumn{2}{|c|}{ Poverty Status } & \multirow[b]{2}{*}{ Overall } \\
\hline & Poor & Non-poor & \\
\hline Vulnerable & $\begin{array}{c}57.1 \\
(95.2)\end{array}$ & $\begin{array}{c}42.9 \\
(18.6)\end{array}$ & 34.4 \\
\hline Non-vulnerable & $\begin{array}{c}1.5 \\
(4.8)\end{array}$ & $\begin{array}{c}98.5 \\
(81.4)\end{array}$ & 65.6 \\
\hline Overall & 20.6 & 79.4 & 100 \\
\hline
\end{tabular}

As shown in Table 2, three estimates of poverty are given as headcount, intensity of poverty and severity of poverty across region. A high incidence of rural poverty (22.7 percent) is observed as compare to urban poverty (14.7 percent). In this manner a high intensity of poverty (the average poverty gap, or the amount of income/expenditure necessary to bring everyone in poverty right up to the poverty line, divided by total households) also observed in all areas of Pakistan. This can be thought of as the amount that an average household in the economy would have to contribute in order for poverty to be just barely eliminated. Furthermore severity of poverty is income inequality among the poor. A high intensity and severity of poverty is seen in rural areas as compare to urban areas and overall Pakistan indicating a high risk of future poverty. In addition to, some districts with high average poverty and vulnerability level can be seen in Figure 1. 
Table 2

FGT Poverty Estimates: 2010

\begin{tabular}{lccc}
\hline & \multicolumn{3}{c}{ Poverty Measures } \\
\cline { 2 - 4 } Region & Headcount & Intensity of Poverty & Severity of Poverty \\
\hline Urban & 14.7 & 2.60 & 0.7 \\
Rural & 22.4 & 5.11 & 1.75 \\
Overall & 20.6 & 4.54 & 1.5 \\
\hline
\end{tabular}

Source: Author's computation is from the micro data of PPHS-2010.

Fig.1. Poverty and Vulnerability

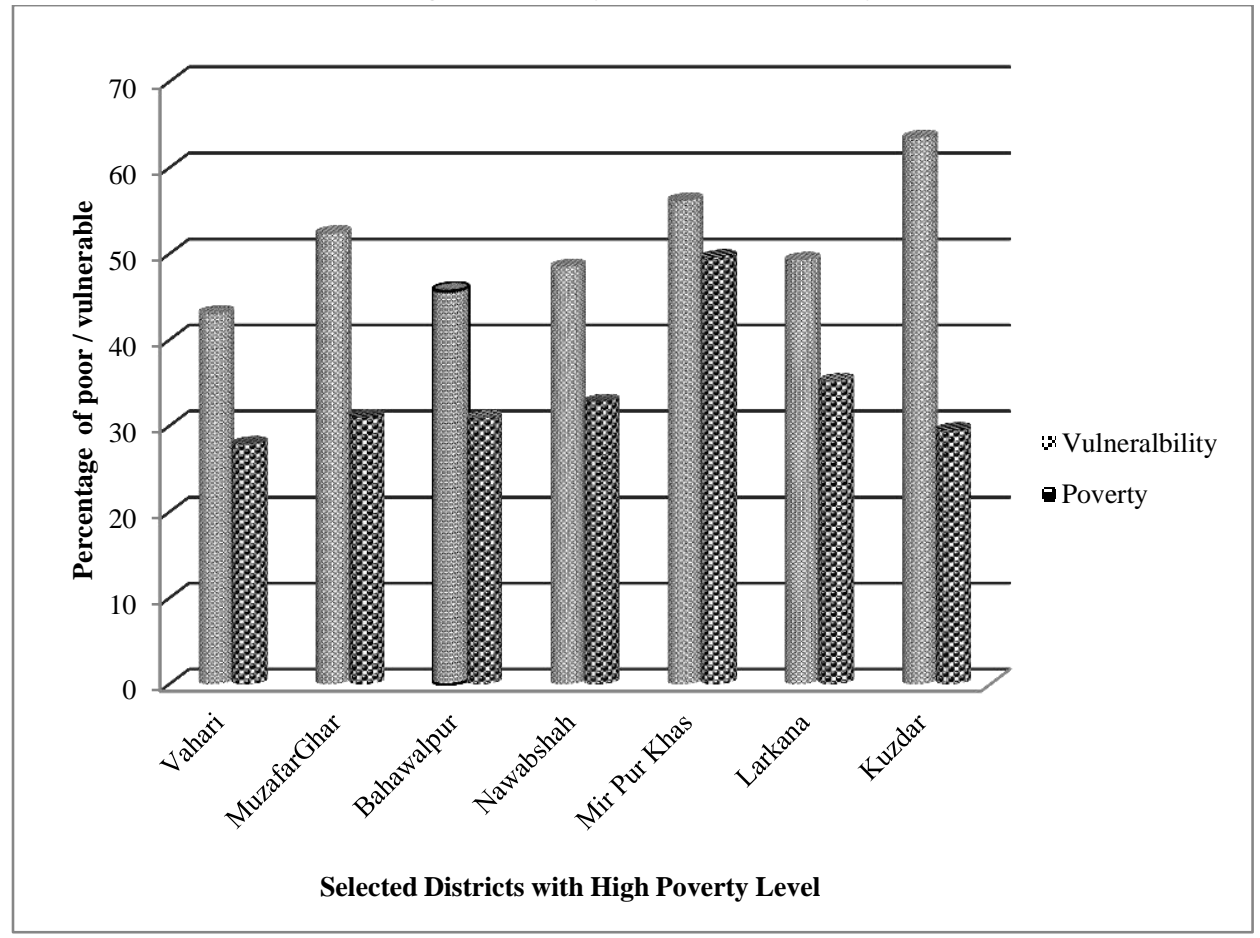

Table 3 presents a cross-distribution of the percentage of vulnerability and poverty for the households who had suffered a welfare loss due to a shock during last five years, 20062010. The welfare loss is measured in terms of income loss which has resulted in consumption variability of food and non-food expenditure. Households and communities in Pakistan face the risks of suffering from different types of shocks that affect communities as a whole referred to as covariate shocks such as natural disasters while others affect one or a few households denoted as idiosyncratic shocks such as a death of household member or loss of a job. Even though, any household can be affected by these shocks, not all of them have the same probability of recovering from the consequences of suffering from them. Poor households are more vulnerable because they lack the necessary physical and human capital to recover from it. All households who are hit by any type of shock have high poverty rates than average poverty level in Pakistan, as demonstrated in Table 3. 
Table 3

Estimates of Vulnerability and Poverty by Type of Shocks: 2010

\begin{tabular}{lccc}
\hline \multirow{2}{*}{ Shocks } & \multicolumn{2}{c}{ Vulnerability and Poverty Status } & Ratio of Vulnerability to \\
\cline { 2 - 3 } & Vulnerable & Poor & Poverty \\
\hline Incidence of Shock & 36.2 & 23.7 & 1.53 \\
Idiosyncratic Shock & 34.2 & 21.4 & 1.60 \\
Covariate Shock & 36.5 & 26.3 & 1.39 \\
Natural/Agriculture & 35.5 & 23.0 & 1.54 \\
Economic & 37.8 & 38.2 & 0.99 \\
Social & 37.0 & 23.3 & 1.59 \\
Health & 36.7 & 23.5 & 1.56 \\
\hline Source: Author's computation is from the micro data of PPHS-2010.
\end{tabular}

In Pakistan covariate shock in the form of flood is a common phenomenon whereby informal insurance mechanism become fail, resulted in high poverty (26.3 percent) and vulnerability ( 36.5 percent). These estimates indicate that the observed incidence of poverty underestimates the fraction of the population that is vulnerable to poverty. The level of underestimation is revealed by the vulnerability to poverty ratio, which is greater than one for all households in 2010. Although incidence of poverty had decreased but the vulnerability and vulnerability to poverty ratio had increased during 2001-05 [Jamal (2009)]. The level of poverty had further decreased in urban and rural areas of Pakistan but the vulnerability and vulnerability to poverty ratio had deteriorated in 2010. This analysis also documented that health shocks are more costly than agriculture ones as can be seen with high poverty and vulnerability. For example, Kenjiro (2005) found that in rural Cambodia, the economic damage caused by sickness is more severe than that caused by a crop loss. Gertler and Gruber (2002) explored evidence that in Indonesia the economic costs associated with major illness are high and cause a severe reduction in household consumption. Moreover, health shocks may prevent households from using some coping strategies, for example households are less likely to use the labour supply to cope with health shocks because they may affect the ability of the households to provide labour [Kochar (1995)]. However, the experience of shock by rich households might have negatively affected other households that depend on them for livelihoods and economic survival.

In developing countries households face substantial risks, which they handle with risk-management and risk-coping strategies, including self-insurance through savings and informal insurance mechanisms but despite these mechanisms, however, they remain vulnerability to high risk. In Table 4 distribution of vulnerability and poverty is given by risk management strategies when a household is encountered by a shock. These ex-post coping strategies can be divided into four main categories: (i) assetbased strategies; (ii) assistance-based strategies; (iii) borrowing-based strategies; and (iv) behaviour-based strategies. The level of vulnerability and poverty is higher for those households who had adopted behaviour-based strategies such as consuming less, increasing labour supply or taking children out of school for work. These types of coping strategies are practiced more often for natural/agricultural shocks than for economic 
Table 4

Vulnerability and Poverty by Risk Management Strategies: 2010

\begin{tabular}{lccc}
\hline Risk Management & \multicolumn{2}{c}{ Vulnerability and Poverty Status } \\
\cline { 2 - 3 } Strategies & Vulnerable & Poor & $\begin{array}{c}\text { Ratio of Vulnerability } \\
\text { to Poverty }\end{array}$ \\
\hline Assets based & 30.8 & 21.9 & 1.41 \\
Assistance based & 38.1 & 25.9 & 1.47 \\
Borrowing based & 40.6 & 24.6 & 1.65 \\
Behavior based & 43.9 & 26.0 & 1.69 \\
One strategy & 36.2 & 23.7 & 1.53 \\
Two strategies & 39.8 & 27.8 & 1.43 \\
Three strategies & 39.5 & 28.5 & 1.39 \\
\hline
\end{tabular}

Source: Author's computation is from the micro data of PPHS-2010.

shocks [Haq (2012)]. In previous studies these finding are also supported by Beegle, et al. (2006) who found that in Tanzania households respond to transitory income shocks by increasing child labour and the extent to which child labour is used as a buffer is lower when households have access to credit. Jacoby and Skoufas (1997) also showed that in India unanticipated income shocks have a significant effect on children school attendance and that school attendance appears to play an important role in the self-insurance strategy of poor households. It is often noted that some households had to adopt more than one strategy for consumption smoothing. The findings in Table 4 demonstrate that those households who had adopted more than one coping strategies are relatively more vulnerable and poor. In addition, these households reduced food consumption, non-food consumption and increased labour supply of children or women in response to shocks as a second coping strategy because they had limited asset base, and face missing formal insurance and finance markets to smooth consumption expenditure.

An individual can be vulnerable to falling below a threshold across several dimensions, such as education, quality of housing, household's productive assets such as land or livestock, and place of residence etc. The estimates given in Table 5 demonstrate that household heads that had up to primary level education are more vulnerable and poor as compared to higher level education As a consequence, this low level of human capital does not allow them to earn enough income to reduce vulnerability. Similarly, households living in mud houses are more vulnerable to poverty as compared to residence of better quality of houses. At the same time households with low level of physical capital are the most vulnerable and hence remain chronically poor. Vulnerability to shocks can be seen a cause of chronic poverty (poor in both periods). However, Okidi and Mugambe (2002) state that vulnerability to shocks is not just a cause of poverty but is also a symptom of poverty. This is highlighted by Baulch and Hoddinot (2000) who state that "households with greater endowments and greater returns will tend to be less vulnerable to shocks. Furthermore, in this analysis those households who are affected by any type of shocks have high incidence of poverty and vulnerability as compared to households with average poverty level in Pakistan. 
Table 5

Estimates of Vulnerability and Poverty across Groups: 2010

\begin{tabular}{lccc}
\hline \multirow{2}{*}{ Groups } & \multicolumn{2}{c}{ Vulnerability and Poverty Status } & $\begin{array}{c}\text { Ratio of Vulnerability } \\
\text { to Poverty }\end{array}$ \\
\cline { 2 - 3 } & Vulnerable & Poor & 1.65 \\
No Schooling & 39.8 & 24.0 & 1.58 \\
Primary education & 39.1 & 24.7 & 1.83 \\
Secondary education & 26.4 & 14.4 & 1.09 \\
Higher education & 10.3 & 9.4 & 1.54 \\
Mud house & 47.4 & 30.8 & 1.81 \\
Mixed (mud and brick house) & 27.7 & 15.3 & 1.91 \\
Brick house & 24.1 & 12.6 & 1.66 \\
Landless households & 37.6 & 22.7 & 1.57 \\
Small landholders (up to 3 acres) & 37.7 & 24.0 & 1.77 \\
Medium landholders ( $3^{+}-10$ acres) & 26.2 & 14.8 & 1.97 \\
Large landholders (10 ${ }^{+}$acres) & 20.9 & 10.6 & 1.67 \\
No livestock & 37.6 & 22.5 & 1.74 \\
Large animals (No.) & 29.5 & 17.0 & 1.71 \\
Small animals (No.) & 35.4 & 20.7 & 2.0 \\
Urban & 29.4 & 14.7 & 1.6 \\
Rural & 35.9 & 22.4 & 1.67 \\
Overall & 34.5 & 20.6 & \\
\hline Source: Author's estimates based & & & \\
\hline
\end{tabular}

Source: Author's estimates based on the micro data of PPHS-2010.

Table 6 presents the results of logit regression of the determinants of vulnerability, where vulnerable households are those who are expected to be perpetually poor or expected to either fall into poverty. The results show that the models produced a good fits of the data as revealed by the statistical significance of the pseudo coefficient of determinations and Wald Chi-square parameters. The analysis shows that as the age of the household head increases, the probability of being vulnerable significantly decreases while large household size significantly increases this probability. Increasing aged/child dependency ratio is another significant variable to increase the probability of vulnerability.

Furthermore, compared to base category 'illiterate head of household', the household heads that had secondary level or high level of education significantly reduces the probability of falling into poverty in future. This is also expected since education is expected to increase capacity for escaping poverty [World Bank (2002)]. The model shows that poor households significantly increases the probability of being poor in future thus remain chronically poor or remain poor in both periods. Physical capital which is related to productive assets such as agriculture land and livestock are important in risk management. The households who had land ownership and large animals are less likely to be vulnerable because, possession of assets leads to an increase in the expectation of future consumption and provide a secure source of income in the face of negative shocks to income. However, households having small animals and residing in lower quality of housing significantly increases the probability of being poor in future. It is also elaborated that households with natural /agricultural shocks, including flood, earthquake, drought, crop failure and loss of livestock, etc. are likely to be more vulnerable as compared to those households who are affected by social shocks while households with health shocks and economic shocks have less probability of being vulnerable. 
Table 6

Determinants of Vulnerability to Poverty in Pakistan

\begin{tabular}{|c|c|c|c|}
\hline \multirow[b]{2}{*}{ Correlates } & \multicolumn{3}{|c|}{ Vulnerable / Non Vulnerable } \\
\hline & Coefficient & Std. Error & $\operatorname{Exp}(\beta)$ \\
\hline Intercept & -3.25 & 1.418 & 0.039 \\
\hline Male headed households & -0.88 & 0.677 & 0.413 \\
\hline Age of HH Head (years) & $-0.12^{* * *}$ & 0.007 & 0.88 \\
\hline Household size (No) & $0.067^{*}$ & 0.027 & 1.069 \\
\hline Primary Education & -0.050 & 0.104 & 0.95 \\
\hline Secondary Education & $-0.23^{* * *}$ & 0.13 & 0.79 \\
\hline Higher Education & $-0.463^{*}$ & 0.119 & 0.63 \\
\hline Dependency ratio & $0.202^{* * *}$ & 0.106 & 1.22 \\
\hline Poverty status & $4.32^{*}$ & 0.25 & 75.17 \\
\hline Land ownership (acres) & $-0.039^{*}$ & 0.01 & 0.96 \\
\hline Large animals (No.) & $-0.413^{*}$ & 0.055 & 0.662 \\
\hline Small animals (No.) & $0.13^{*}$ & 0.022 & 1.139 \\
\hline Housing quality (mud house) & $1.26^{*}$ & 0.562 & 3.53 \\
\hline Agriculture shocks & $1.054^{*}$ & 0.274 & 2.86 \\
\hline Economic shocks & $-3.33^{*}$ & 0.499 & 0.036 \\
\hline Health shocks & $-1.36^{*}$ & 0.279 & 0.26 \\
\hline Covariate shock & -0.016 & 0.25 & 0.98 \\
\hline Cost of shock (Rs.) & $0.366^{*}$ & 0.082 & 1.44 \\
\hline Asset based strategy & $-2.08^{*}$ & 0.246 & 0.13 \\
\hline Assistance based strategy & $-2.14^{*}$ & 0.357 & 0.12 \\
\hline Borrowing based strategy & $-1.36^{*}$ & 0.284 & 0.26 \\
\hline Multi strategies & 0.203 & 0.047 & 1.23 \\
\hline Region (Rural=1) & $0.397^{*}$ & 0.110 & 1.48 \\
\hline Punjab & $-0.443^{* * *}$ & 0.24 & 0.64 \\
\hline Sindh & $-0.734^{*}$ & 0.25 & 0.48 \\
\hline KPK & $-1.48^{*}$ & 0.295 & 0.227 \\
\hline Chi-square & & 2874.37 & \\
\hline-2 Log likelihood & & $4807 . .32$ & \\
\hline Pseudo R ${ }^{2}$ (Cox and Snell) & & 0.152 & \\
\hline Observations & & 3500 & \\
\hline
\end{tabular}

Source: Author's estimates based on the micro data of PPHS-2010.

a. The reference category is: Non Vulnerable households.

${ }^{*}$ significant at 1 percent, ${ }^{* *}$ significant at 5 percent and significant at ${ }^{* * *} 10$ percent.

When economic hardships occur in developing countries, people resort to various risk coping strategies to smooth consumption, since formal credit and insurance markets are less developed. In this analysis different types of risk management strategies are adopted by households showing that households who had adopted assets, assistant and borrowing based strategies are less likely to be vulnerable as compared to those who had adopted behaviour based strategies. These strategies includes decrease food and non-food consumption, increase labour supply particularly of women and children, beggary/ 
prostitution, children drop out from school and sent to work and bonded labour arrangements, thus had inter-generational transmission of poverty and vulnerability. The final set of results concerns the geographical locations that also play an important role in determining a household to be vulnerable to poverty. Rural households are more vulnerable as compared to urban residents while households living in province of Punjab, $\mathrm{KP}$ and Sindh are less vulnerable as compared to Balochistan.

\section{CONCLUSIONS}

The well-being of poor households depends not only on households' current consumption or expenditures, but also on risk and uncertainty about their future welfare. This paper has developed a measure of vulnerability to poverty that takes both permanent and transitory household characteristics into consideration to forecast vulnerability. The methodology involves a three stage FGLS method for generating vulnerability indices by employing PPHS-2010 data.

The analysis highlights that total vulnerability is found to be 34.4 percent as opposed to the poverty of 20.7 percent. Vulnerability in rural areas is even higher which is estimated to be 35.9 percent as oppose to 29.4 percent of urban statistic. When decomposing vulnerability into poor and non-poor households, it was figured out that 95 percent poor households are also vulnerable while only 18 percent non-poor households are vulnerable. Risks to livelihood are particularly important in Pakistan where there is generally high dependence on agriculture sector. Households who had suffered a welfare loss due to a shock particularly covariate shocks are more vulnerable to poverty. High vulnerability and poverty is found for those households who suffered from agriculture, social, economic and health shocks during the last five years. In addition the ratio of vulnerability to poverty is also high for agricultural, social, health and idiosyncratic shocks. When these shocks occur, household resort to various risk coping strategies to smooth consumption, since formal credit and insurance markets are less developed. Households who had adopted borrowing or behaviour based strategies are more likely to be vulnerable to poverty. The more one is vulnerable, the less one has the capacity to cope, the more one tends to adopt multiple coping mechanisms hence these households are more vulnerable to poverty as observed in this analysis. The study also revealed that households may be vulnerable across several dimensions, such as no schooling, low quality housing, no productive assets and geographical location. The model measuring determinants of vulnerability indicate that households head with no education, large family size, high number of dependents, poverty status, lack of productive assets, agriculture shocks, high cost of shock and rural residence have significantly higher probability of being poor in future.

Finally, a clear observation in this analysis is that vulnerability and poverty is still concentrated in Pakistan. It is important to build productive assets for the poor and vulnerable households, increasing the coverage of education and health, and strengthen the disaster management and relief mechanisms. In addition, this paper argues that despite the limitations of purely cross-sectional data, an analysis of this data can potentially be informative for poverty alleviation programmes. 


\section{REFERENCES}

Arif, G. M and Shujaat Farooq (2012) Rural Poverty Dynamics in Pakistan: Evidence from Three Waves of the Panel Survey. Pakistan Institute of Development Economics, Islamabad. (Poverty and Social Dynamics Paper Series, PSDPS-2).

Baulch, B. and J. Hoddinott (2000) Economic Mobility and Poverty Dynamics in Developing Countries. Journal of Development Studies 36:6, 1-24.

Beegle, K, Rajeev H. Dehejia, and Roberta Gatti (2006) Child Labour and Agricultural Shocks. Journal of Development Economics 81, 80-96.

Chaudhuri, S. (2000) Empirical Methods for Assessing Household Vulnerability to Poverty, Columbia University. (Draft).

Chaudhuri, S. (2003) Assessing Vulnerability to Poverty: Concepts, Empirical Methods and Illustrative Examples. Columbia University. (Mimeographed).

Chaudhuri, S., J. Jalan, and A. Suryahadi (2002) Assessing Household Vulnerability to Poverty from Cross-Sectional Data: A Methodology and Estimate from Indonesia. Columbia University. (Mimeographed).

Christiaensen, L. J. and K. Subbarao (2005) Towards an Understanding of Household Vulnerability in Rural Kenya. Journal of African Economies 14:4, 520-558.

Dercon, S. and P. Krishnan (2000) Vulnerability, Seasonality and Poverty in Ethiopia. Journal of Development Studies 36:6, 25-53.

Foster, J., J. Greer, and E. Thorbecke (1984) A Class of Decomposable Poverty Measures. Econometrica 52, 761-776.

Gertler, P. and J. Gruber (2002) Insuring Consumption against Illness. American Economic Review 92:1, 55-70.

Gujarati, D. N. (2012) Basic Econometrics (Fifth Edition). New York: Tata McGrawHill Companies. Inc.

Günther, I. and K. Harttgen (2005) Vulnerability to Poverty in Madagascar. Background Paper prepared for the World Bank Social Protection Unit.

Haq, R. (2012) Shocks as a Source of Vulnerability: An Empirical Investigation from Pakistan. Pakistan Institute of Development Economics. (Poverty and Social Dynamics Paper Series PSDPS: 6)

Heltberg, R. and L. Niels (2009) Shocks, Coping, and Outcomes for Pakistan's Poor: Health Risks Predominate. Journal of Development Studies 45:6, 889-910.

Holzmann, R. and S. Jørgensen (2000) Social Risk Management: A New Conceptual Framework for Social Protection and Beyond. World Bank. (Social Protection Discussion Paper No. 0006).

Jacoby, H. and E. Skoufias (1997) Risk, Financial Markets, and Human Capital in a Developing Country. Review of Economic Studies 64:3, 311-335.

Jalan J. and M. Ravallion (1999) Are the Poor less Well Insured? Evidence on Vulnerability to Income Risk in Rural China. Journal of Development Economics $58: 1,61-81$.

Jamal, H. (2009) Assessing Vulnerability to Poverty: Evidence from Pakistan. Social Policy and Development Centre (SPDC). Islamabad. (Research Report No.80).

Kenjiro, Y. (2005) Why Illness Causes More Serious Economic Damage than Crop Failure in Rural Cambodia. Development and Change 36: 4, 759-783. 
Kochar, A. (1995) Explaining Household Vulnerability to Idiosyncratic Income Shocks. American Economic Review 85:2, 159-164.

Kurosaki, T. (2010) Targeting the Vulnerable and the Choice of Vulnerability Measures: Review and Application to Pakistan. The Pakistan Development Review 49:2, 87-103.

Ligon, E. and L. Schechter (2003) Measuring Vulnerability. Economic Journal 113, C95C102.

Mansuri, Ghazala and Andrew Healy (2002) Vulnerability Predictions in Rural Pakistan, IFPRI-World Bank Conference on Risk and Vulnerability: Estimation and Policy Implications.

Morduch J. (2005) Consumption Smoothing across Space: Testing Theories of RiskSharing in the ICRISAT Study Region of South India. In S. Dercon (ed.) Insurance against Poverty. Oxford: Oxford University Press.

Okidi, J. and G. Mugambe (2003) An Overview of Chronic Poverty and Development Policy in Uganda. Chronic Poverty Research Centre, Manchester, UK. (CPRC Working Paper 11).

Pakistan, Government of (2010) Economics Survey of Pakistan, 2009-10. Economic Advisor‘s Wing, Finance Division, Islamabad.

Suryahadi, A. and S. Sumarto (2003) Poverty and Vulnerability in Indonesia before and after the Economic Crises. Asian Economic Journal 17:1.

Tesliuc, and L. Kathy (2004) Risk and Vulnerability in Guatemala: A Quantitative and Qualitative Assessment. Social Protection Unit, Human Development Network. The World Bank.

Townsend, Robert (1994) Risk and Insurance in Village India. Econometrica 62:3, 539591.

Udry, C. (1995) Risk and Saving in Northern Nigeria. The American Economic Review $85: 5,1287-1300$.

UNDP (2014) Sustaining Human Progress: Reducing Vulnerabilities and Building Resilience. Human Development Report, 2007/2008. United Nations Development Programme.

UNISDR (2004) Living With Risk. United Nations International Strategy for Disaster Reduction, Geneva, Switzerland.

World Bank (2002) World Development Report 2002. Washington, DC: World Bank. 